\title{
Breastfeeding and infant feeding guidelines: dietary patterns and potential effects on the health and nutrition of children under two years
}

Isadora Nogueira Vasconcelos 1

iD https://orcid.org/0000-0002-6608-2112

Ilanna Maria Vieira de Paula de Brito 2

iD https://orcid.org/0000-0003-0995-7485

Soraia Pinheiro Machado Arruda 3

(iD https://orcid.org/0000-0002-3918-4738

Daniela Vasconcelos de Azevedo 4

(iD https://orcid.org/0000-0003-2789-7471

1 Centro Universitário Fametro. Rua Conselheiro Estelita, 500. Centro. Fortaleza, CE, Brasil. CEP: 60.010-260. E-mail: E-mail: isadora-nv@hotmail.com

2-4 Universidade Estadual do Ceará. Fortaleza, CE, Brasil.

\begin{abstract}
Objectives: to identify dietary patterns of children under two years of age in primary care, associating them with maternal variables.

Methods: cross-sectional study carried out in basic health units. Sample selected for convenience with 321 children under two years old and their mothers. Food consumption was obtained through a 24-hour food record. The method of factor analysis by main components was used to determine dietary patterns. Associations between maternal variables and dietary patterns were tested.

Results: "mixed", "porridge" and "snacks" patterns were identified. Receiving guidance on infant feeding was related to greater adherence to the "mixed" $(p=0.02 ; P R=2.98 ; 95 \%$ $C I 95 \%=1.49-5.96)$ and "porridge" ( $p=0.026 ; P R=2.10 ; C I 95 \%=1.09-4.02)$ patterns. Experience with breastfeeding showed greater adherence to the "porridge" standards $(p=0.038 ; P R=1.78 ; C 195 \%=1.03-3.08)$ and "snacks" $(p=0.026 ; P R=1.09 ; C 195 \%=$ 1.01-1.18) and children of overweight mothers showed less adherence to the "snacks" pattern $(p=0.042 ; P R=0.51 ; C 195 \%=0.26-0.98)$.

Conclusions: patterns found were associated with guidance on infant feeding and breastfeeding, previous experience with breastfeeding, as well as with maternal excess weight, emphasizing the importance of professional guidance for greater adherence to more varied and healthy consumption patterns and that include the different food groups.
\end{abstract}

Key words Food patterns, Child feeding, Mothers, Factor analysis

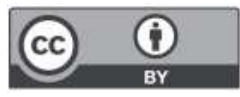




\section{Introduction}

The first thousand days of life are a critical period of child development, with repercussions on adult life. Actions given to children in this period aim to reduce child mortality, obesity and chronic diseases in childhood and adulthood, adequate cognitive, motor and socio-affective development, better learning capacity and consequent increase in work capacity and productivity. Breastfeeding and complementary feeding are important pillars to achieve these goals. 1,2

The initial experiences of feeding children with new flavors, smells and textures, especially in the first year of life, should be valued, as they can define their preferences of tastes and flavors, and with that, facilitate or hinder the adoption of healthy practices from the very beginning of life, in addition to being able to favor the scenario for a healthy food future, which will play an important role in protecting against diseases. ${ }^{3}$

The evaluation of the food consumption of Brazilian children shows inadequate practices, such as early weaning, consumption of foods not suitable for the age group, such as cow's milk, sugar and honey before one year of life; insufficient intake of fruits, vegetables, meats and beans; early exposure to ultra-processed foods. In addition to these inadequacies, it is observed that the daily diet is, in most cases, monotonous and in inadequate quantity, frequency and consistency. $4,5,6$

Although studies on food consumption in the age group under 24 months are common, the focus is usually on nutrient intake, composition and adequacy of the diet, with little determination of dietary patterns. The use of standards as a method of investigating food intake arises from the need for assessing consumption from the perspective of the set of foods eaten, in combinations, through meals and not only contemplate an approach to the action of nutrients or isolated foods. $7,8,9$

Thus, the definition of eating patterns of children under two years of age plays an important role in determining nutritional status and nutritional risks, such as overweight and specific nutritional deficiencies, in addition to developmental deviations and other negative outcomes. Thus, the objective of the present investigation was to identify the main dietary patterns of children under two years of age treated in Primary Health Care in the city of Fortaleza, Ceará and their association with maternal variables.

\section{Methods}

The present study is cross-sectional, with a quantitative approach. It was developed in seven Primary Health Care Units (PHCU) belonging to the Regional Executive Secretariats of the city of Fortaleza, Ceará, chosen by lot.

The sample was selected for convenience and included 321 children and 319 mothers (two of whom had two children included in the survey), attending the PHCU during the data collection period, December 2015 to August 2016

Children under two years of age (zero to 23 months and 29 days) enrolled in the health unit and their mothers, aged 19 or older and directly responsible for feeding the child were included in the sample. In addition to these criteria, children also needed to have all meals at home and not have any pathology that required special food.

All field researchers (nutritionists and nutrition students) were duly trained in the application of data collection techniques (interview, assessment of anthropometric measures and application of a food survey).

The following maternal variables were identified: age, education, income, number of children, nutritional status, receiving guidance on breastfeeding and infant feeding, previous experience with breastfeeding. The children variables were age, child's birth weight, gestational age at birth, prevalence, type and duration of breastfeeding.

The categorization of variables for analysis of associations was based on gestational risk factors, due to the influence of maternal conditions on the children's health in the first years of life and possible interference in determining their eating patterns. For maternal age, the cut-off point for high-risk pregnancies was used, which is greater than 35 years. For education, it was considered low education when the mother had studied up to elementary education. ${ }^{10}$

For the anthropometric assessment of mothers, data on weight and height were collected, according to recommendations of the Food and Nutrition Surveillance System (SISVAN). 11 The Body Mass Index (BMI) was calculated and classified according to the cutoff point defined in the study (less than 25 $\mathrm{kg} / \mathrm{m}^{2}$, referring to the diagnoses of thinness and eutrophy and greater than or equal to $25 \mathrm{~kg} / \mathrm{m}^{2}$, which reveals overweight)

Food consumption data for children under two years of age were investigated using a 24-hour food record (R24h) to obtain dietary patterns. The use of only one R24h was due to the fact that information on the consumption of just one day is acceptable 
when dealing with populations with very monotonous food, 12 since many children were in the process of introducing complementary food, which lead the variation in feeding in a short period of time to be small. Three hundred and ten (310) recalls were included, being excluded 11 forms due to incomplete filling.

To quantify breast milk consumed, we chose to use the Drewett et al.13 equation that estimates the volume of breast milk consumed using a multiple linear regression model that uses the child's age in days: $\mathrm{Y}=734.3-0.85 \mathrm{X}$, where $\mathrm{Y}$ is the predictor of milk intake and $X$, age in days. Some Brazilian studies used the proposed equations, Drewett et al. 13,14

Foods mentioned in the R24h were listed and grouped according to the nutritional composition, characteristics regarding the habit of the Brazilian population and based on categories already used in other studies to identify dietary patterns (Table 1).

To identify patterns, we opted for the principal component analysis (PCA) method, carried out by means of the following steps: Assessment of the adequacy of the data to the factor analysis using the Kaiser-Meyer-Olkin coefficient (KMO>0.50) and Bartlett's test of sphericity (BST $<0.05$ ); extraction of component factors, by defining the number of factors retained, using the eigenvalues evaluation criteria, which must be greater than 1.0 and the Cattel graph (scree plot), in which the points on the largest slope indicated the appropriate number of factors to be retained and the subjective interpretation of the identified eating patterns 8,15 ; Rotation of the factors retained by the varimax orthogonal method; Interpretation of each main component according to its factor loads (correlation coefficients between the dietary variables and the factors). In the last phase, each main component was named based on the foods present.8,15,16 Individuals received a factorial score for each retained pattern.

Each main component was interpreted according to the factorial loads of the food, being considered important those with loads $\geq 0.3$ or $\leq-0.3$. Negative loads indicate an inverse association of the food item with the pattern, whereas positive loads indicate a direct association. ${ }^{15,17}$ The factor scores of each food pattern were categorized in quartiles, in which the upper quartile of the distribution represents a greater adherence to the pattern.

For data statistical analysis, a descriptive analysis of the variables under study was initially carried out, with the continuous variables being presented by means (standard deviation), and the categorical variables by simple frequencies and percentages. The normality of the numerical variables was assessed using the Shapiro Wilk test.

Poisson regression with robust variance estimation was used in the bivariate and multivariate analysis to estimate the prevalence ratios (PR) of the independent variables (socioeconomic and demographic factors), in relation to the outcomes/dependent variables (food consumption patterns), classifying these as dichotomous: low consumption (1st and $2^{\text {nd }}$ quartiles) and high consumption (3rd quartile). The model was adjusted for the variables: age, BMI, number of children, education, previous experience with breastfeeding, having received guidance on breastfeeding and having received guidance on infant feeding. The estimates were calculated by points and by $95 \%$ Confidence Intervals (CI). Statistical analyses were performed on STATA, version 10.0, adopting a significance level $(p)$ of $5 \%$. This study is an excerpt from the research "The maternal and child healthcare network in Fortaleza: caring for pregnant women, nursing mothers and children under two years old" (Edital Universal 14/2013 - CNPq; Process: 484077/2013-9), approved by the Research Ethics Committee of the State University of Ceará (UECE), CAAE: 14911313.0.0000.5534. Data collection occurred after the signing of the Informed Consent Form by the participating mothers.

\section{Results}

Mothers were under 35 years old $(82.8 \%)$, with high school or university education $(72.4 \%)$, income between one and three minimum wages $(76.4 \%)$ and $93.1 \%$ of them had one to three sons. The assessment of nutritional status showed that $49.7 \%$ were overweight. More than half of mothers were informed about breastfeeding $(77.9 \%)$ and infant feeding $(51.4 \%)$ by health professionals. Previous experience with breastfeeding was reported by $52.4 \%$ of them.

Almost half of the children were less than six months old (49.8\%), 25.6\% between 6 and 12 months and $24.6 \%$ between 12 and 24 months. Most children were born at term $(86.7 \%)$ and with adequate weight $(85.2 \%)$.

The prevalence of breastfeeding was $96.3 \%$ and the mean duration of exclusive breastfeeding (EBF) was 3.37 months \pm 2.09 . Exclusive breastfeeding for six months was identified in $23.3 \%$ of children.

In the definition of dietary patterns, a KMO coefficient of 0.7752 was found, which indicated the adequacy of the data for conducting factor analysis by main components. Six factors with eigenvalues 
$\geq 1.0$ were retained. From the interpretation of the retained factors, three main dietary patterns were identified, also based on the interpretation of their components, which explained $48.45 \%$ of the total variance.

The dietary patterns identified were named as follows: "mixed" pattern represented by fruits, vegetables, cereals and tubers, meat, chicken, fish

\section{Table 1}

Grouping of foods mentioned in the 24-hour food records of children under two years of age.

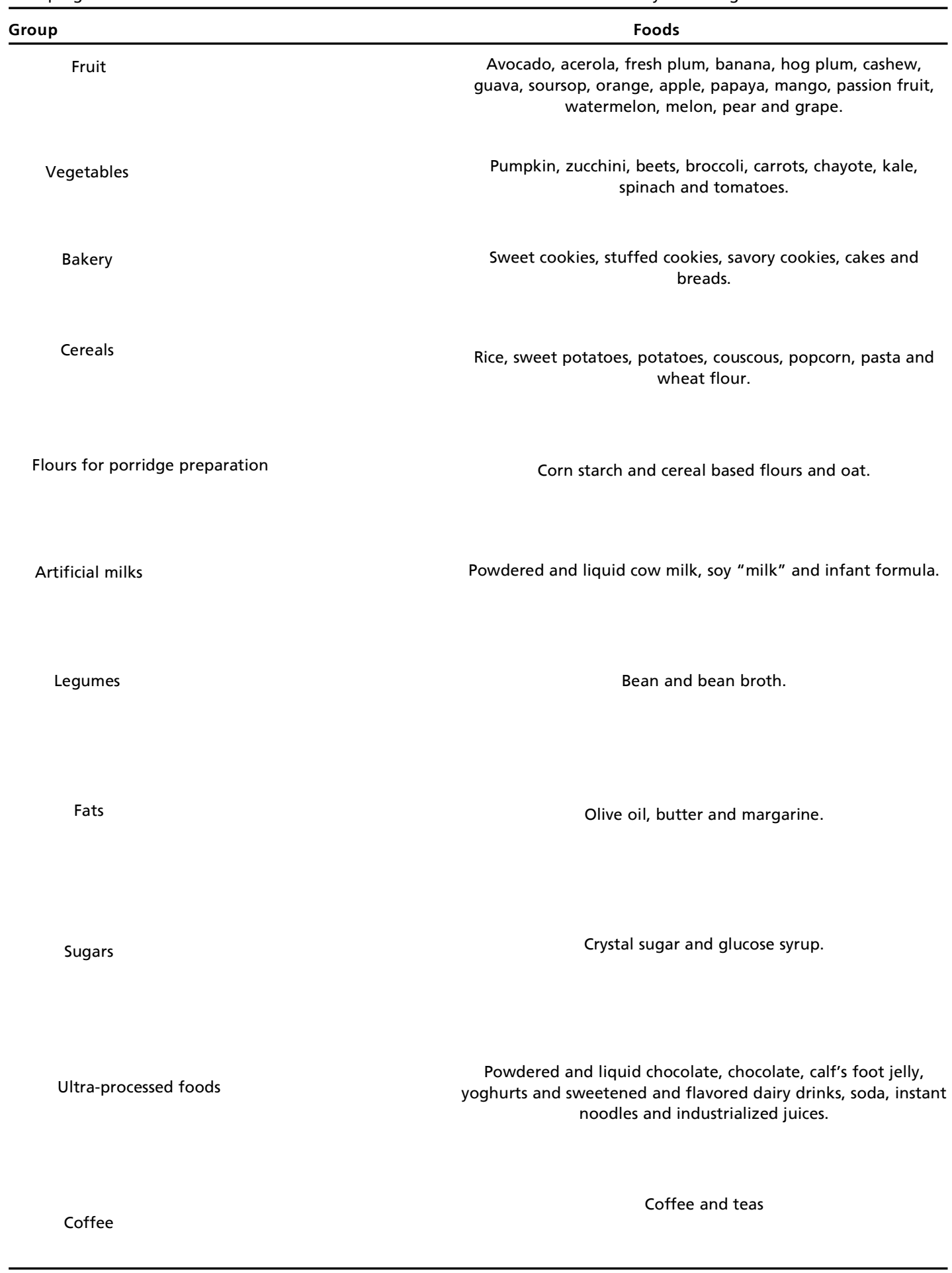


and eggs, sugars and ultra-processed foods; "porridge" pattern, consisting of porridge flours, artificial milk and sugar and "snacks" pattern, characterized by bakery products, legumes, fats and coffee. Breastfeeding had a negative charge in the "porridge" pattern, thus showing an inverse association with this pattern. The "mixed" pattern explained the greater proportion of the total variance $(27.35 \%)$ (Table 2)

The association between maternal variables and the dietary patterns obtained showed that mothers who received guidance on infant feeding had greater adherence to the "mixed" pattern ( $p=0.02$ $\mathrm{PR}=2.98$; CI95\% $=1.49-5.96)$ (Table 3$)$ also to the "porridge" pattern $(p=0.026 ; \mathrm{PR}=2.10 ; \mathrm{CI} 95 \%=$ 1.09-4.02) (Table 4). Mothers who received guidance on breastfeeding had less adherence to the "snacks" pattern $(p=0.014 ; \mathrm{PR}=0.44 ;$ CI95\% $=$ $0.22-0.85$ ) (Table 5)

Having previous experience with breastfeeding showed greater adherence to the "porridge" pattern $(p=0.038 ; \mathrm{PR}=1.78 ; \mathrm{CI} 95 \%=1.03-3.08)($ Table 4). Children whose mothers were overweight or obese (BMI $\geq 25 \mathrm{~m} / \mathrm{kg}^{2}$ ) showed less adherence to the "snacks" pattern ( $p=0.042 ; \mathrm{PR}=0.51 ; \mathrm{CI} 95 \%=$ 0.26-0.98) (Table 5). No association was found between the other variables and the patterns (Tables 3,4 and 5)

\section{Discussion}

The "mixed" pattern included healthy foods, which should be used in the diet of children under two years old, such as fruits, vegetables, cereals and tubers, meat, chicken, fish and eggs. However, groups of non-recommended foods, such as sugars and ultra-processed foods, were also included.18

The presence of fruits and sugars in this pattern denotes the joint use of these foods in the preparation of juices and milkshakes with fruits. The presence of ultra-processed foods, mostly represented by sweetened and flavored yoghurts, a food that has status for the poorest population. 19

The "porridge" pattern composed of flour, artificial milk and sugar points to the high consumption of porridges that are prepared, most of the time, with cow milk and sugar. Breastfeeding showed an inverse association with this pattern, that is, those who consumed porridge, did not consume breast milk, showing that the introduction of these foods harms breastfeeding. 18

A similar pattern was found by Matos et al., 4 in a study carried out in Bahia with children under six months, in which, in "food pattern 1", flours, cow milk and derivatives and sugars, with positive charges and breast milk were included, with negative charge, indicating a substitution of breast milk

Table 2

Distribution of the factorial loads of the main dietary patterns identified among children under two years attended at Primary Health Care Units, Fortaleza, CE, 2017.

\begin{tabular}{lccc}
\hline Food groups & Mixed & Porridge & Snacks \\
\hline Cereals and tubers & 0.86 & - & - \\
Meat, chicken, fish and eggs & 0.80 & - & - \\
Vegetable & 0.76 & - & - \\
Fruit & 0.74 & 0.37 & - \\
Sugar & 0.44 & - & - \\
Ultra-processed products & 0.35 & 0.88 & - \\
Flours for porridge & - & 0.88 & - \\
Artificial milk & - & -0.65 & - \\
Breast milk & - & - & 0.72 \\
Fats & - & - & 0.66 \\
Coffee & - & - & 0.63 \\
Bakery & - & 10.96 & 0.37 \\
Legumes & - & 1.64 & 1.52 \\
Explained variance (\%) & & & \\
Eigenvalue & 27.35 & & \\
& 4.10 & & \\
\end{tabular}

Foods with factor loads $\geq 0.3$ or $\leq-0.3$; total variance $=48.45 \%$ 
Table 3

Prevalence ratios (PR), crude and adjusted, and confidence intervals (C195\%) for the association of maternal variables with the "mixed" pattern, Fortaleza, CE, 2017.

\begin{tabular}{|c|c|c|c|c|}
\hline \multirow[t]{2}{*}{ Variable } & \multicolumn{4}{|c|}{ Mixed } \\
\hline & Unadjusted PR & $\mathrm{Cl} 95 \%$ & Adjusted PR & $\mathrm{Cl} 95 \%$ \\
\hline Education & \multicolumn{2}{|c|}{$p=0.952$} & \multicolumn{2}{|c|}{$p=0.573$} \\
\hline Elementary school & Refer. & --- & Refer. & --- \\
\hline High school and university & 1.00 & 0.93-1.07 & 0.82 & $0.41-1.63$ \\
\hline Number of children & \multicolumn{2}{|c|}{$p=0.784$} & \multicolumn{2}{|c|}{$p=0.360$} \\
\hline$\leq 3$ & Refer. & --- & Refer. & --- \\
\hline$>3$ & 1.01 & $0.95-1.07$ & 1.66 & $0.56-4.95$ \\
\hline Age (years) & \multicolumn{2}{|c|}{$p=0.897$} & \multicolumn{2}{|c|}{$p=0.902$} \\
\hline$<35$ & Refer. & --- & Refer. & --- \\
\hline$\geq 35$ & 1.01 & $0.93-1,09$ & 0.94 & $0.37-2.39$ \\
\hline BMI & \multicolumn{2}{|c|}{$p=0.318$} & \multicolumn{2}{|c|}{$p=0.163$} \\
\hline$<25 \mathrm{Kg} / \mathrm{m}^{2}$ & Refer. & --- & Refer. & --- \\
\hline$\geq 25 \mathrm{Kg} / \mathrm{m}^{2}$ & 0.94 & $0.82-1.07$ & 0.62 & $0.31-1.22$ \\
\hline Experience with $\mathrm{BF}$ & \multicolumn{2}{|c|}{$p=0.821$} & \multicolumn{2}{|c|}{$p=0.435$} \\
\hline No & Refer. & -.- & Refer. & -.- \\
\hline Yes & 0.99 & $0.91-1.08$ & 1.26 & $0.70-2.27$ \\
\hline Guidance on BF & \multicolumn{2}{|c|}{$p=0.695$} & \multicolumn{2}{|c|}{$p=0.218$} \\
\hline No & Refer. & --- & Refer. & --- \\
\hline Yes & 1.01 & $0.95-1.07$ & 0.63 & $0.30-1.31$ \\
\hline Guidance on IF & \multicolumn{2}{|c|}{$p<0.001$} & \multicolumn{2}{|c|}{$p=0.002$} \\
\hline No & Refer. & --- & Refer. & --- \\
\hline Yes & 1.16 & $1.08-1.25$ & 2.98 & $1.49-5.96$ \\
\hline
\end{tabular}

$p$-value for the maximum likelihood ratio test obtained using Poisson regression. $\mathrm{BMI}=$ body mass index; $\mathrm{BF}=$ breastfeeding; $\mathrm{IF}=$ infant feeding.

Table 4

Prevalence ratios (PR), crude and adjusted, and confidence intervals (C195\%) for the association of maternal variables with the "porridge" pattern, Fortaleza, CE, 2017.

\begin{tabular}{|c|c|c|c|c|}
\hline \multirow[t]{2}{*}{ Variable } & \multicolumn{4}{|c|}{ Porridge } \\
\hline & Unadjusted PR & $\mathrm{Cl} 195 \%$ & Adjusted PR & $\mathrm{Cl} 95 \%$ \\
\hline Education & \multicolumn{2}{|c|}{$p=0.138$} & \multicolumn{2}{|c|}{$p=0.245$} \\
\hline Elementary school & Refer. & --- & Refer. & --- \\
\hline High school and university & 1.05 & $0.99-1.11$ & 1.68 & $0.70-4.02$ \\
\hline Number of children & \multicolumn{2}{|c|}{$p=0.814$} & \multicolumn{2}{|c|}{$p=0.667$} \\
\hline$\leq 3$ & Refer. & --- & Refer. & --- \\
\hline$>3$ & 0.99 & $0.94-1.05$ & 0.78 & $0.26-2.39$ \\
\hline Age (years) & \multicolumn{2}{|c|}{$p=0.830$} & \multicolumn{2}{|c|}{$p=0.942$} \\
\hline$<35$ & Refer. & --- & Refer. & --- \\
\hline$\geq 35$ & 0.99 & $0.91-1.08$ & 0.97 & $0.48-1.99$ \\
\hline $\mathrm{BMI}$ & \multicolumn{2}{|c|}{$p=0.889$} & \multicolumn{2}{|c|}{$p=0.875$} \\
\hline$<25 \mathrm{Kg} / \mathrm{m}^{2}$ & Refer. & --- & Refer. & --- \\
\hline$\geq 25 \mathrm{Kg} / \mathrm{m}^{2}$ & 1.01 & $0.89-1.14$ & 0.96 & $0.54-1.69$ \\
\hline
\end{tabular}

$p$-value for the maximum likelihood ratio test obtained using Poisson regression $\mathrm{BF}=$ breastfeeding; $\mathrm{IF}=$ infant feeding. 
Prevalence ratios (PR), crude and adjusted, and confidence intervals (CI95\%) for the association of maternal variables with the "porridge" pattern, Fortaleza, CE, 2017.

\begin{tabular}{|c|c|c|c|c|}
\hline \multirow[t]{2}{*}{ Variable } & \multicolumn{4}{|c|}{ Porridge } \\
\hline & Unadjusted PR & $\mathrm{Cl} 95 \%$ & Adjusted PR & $\mathrm{Cl} 95 \%$ \\
\hline Experience with BF & \multicolumn{2}{|c|}{$p=0.772$} & \multicolumn{2}{|c|}{$p=0.038$} \\
\hline No & Refer. & -- & Refer. & --- \\
\hline Yes & 1.01 & $0.93-1.10$ & 1.78 & $1.03-3.08$ \\
\hline Guidance on BF & \multicolumn{2}{|c|}{$p=0.513$} & \multicolumn{2}{|c|}{$p=0.778$} \\
\hline No & Refer. & --- & Refer. & --- \\
\hline Yes & 1.02 & $0.96-1.08$ & 0.90 & $0.43-1.89$ \\
\hline Guidance on IF & \multicolumn{2}{|c|}{$p=0.120$} & \multicolumn{2}{|c|}{$p=0.026$} \\
\hline No & Refer. & --- & Refer. & --- \\
\hline Yes & 1.07 & $0.98-1.16$ & 2.10 & $1.09-4.02$ \\
\hline
\end{tabular}

$p$-value for the maximum likelihood ratio test obtained using Poisson regression

$\mathrm{BF}=$ breastfeeding; $\mathrm{IF}=$ infant feeding.

\section{Table 5}

Prevalence ratios (PR), crude and adjusted, and confidence intervals (CI95\%) for the association of maternal variables with the "snacks" pattern, Fortaleza, CE, 2017.

\begin{tabular}{|c|c|c|c|c|}
\hline \multirow[t]{2}{*}{ Variable } & \multicolumn{4}{|c|}{ Snacks } \\
\hline & Unadjusted PR & $\mathrm{Cl} 95 \%$ & Adjusted PR & $\mathrm{Cl} 95 \%$ \\
\hline Education & \multicolumn{2}{|c|}{$p=0.153$} & \multicolumn{2}{|c|}{$p=0.258$} \\
\hline Elementary school & Refer. & --- & Refer. & --- \\
\hline High school and university & 0,95 & $0.89-1.02$ & 0.69 & $0.36-1.32$ \\
\hline Number of children & \multicolumn{2}{|c|}{$p=0.019$} & \multicolumn{2}{|c|}{$p=0.180$} \\
\hline$\leq 3$ & Refer. & --- & Refer. & --- \\
\hline$>3$ & 1.09 & $1.01-1.17$ & 1.91 & $0.74-4.90$ \\
\hline Age (years) & \multicolumn{2}{|c|}{$p=0.830$} & \multicolumn{2}{|c|}{$p=0.734$} \\
\hline$<35$ & Refer. & --- & Refer. & --- \\
\hline$\geq 35$ & 0.99 & $0.91-1.08$ & 0.86 & $0.35-2.09$ \\
\hline BMI & \multicolumn{2}{|c|}{$p=0.305$} & \multicolumn{2}{|c|}{$p=0.042$} \\
\hline$<25 \mathrm{Kg} / \mathrm{m}^{2}$ & Refer. & --- & Refer. & --- \\
\hline$\geq 25 \mathrm{Kg} / \mathrm{m}^{2}$ & 0.93 & $0.82-1.06$ & 0.51 & $0.26-0.98$ \\
\hline Experience with BF & \multicolumn{2}{|c|}{$p=0.026$} & \multicolumn{2}{|c|}{$p=0.223$} \\
\hline No & Refer. & --- & Refer. & --- \\
\hline Yes & 1.09 & $1.01-1.18$ & 1.46 & $0.79-2.71$ \\
\hline Guidance on BF & \multicolumn{2}{|c|}{$p=0.371$} & \multicolumn{2}{|c|}{$p=0.014$} \\
\hline No & Refer. & --- & Refer. & --- \\
\hline Yes & 0.97 & $0.91-1.03$ & 0.44 & $0.22-0.85$ \\
\hline Guidance on IF & \multicolumn{2}{|c|}{$p=0.089$} & \multicolumn{2}{|c|}{$p=0.074$} \\
\hline No & Refer. & --- & Refer. & --- \\
\hline Yes & 1.07 & $0.99-1.16$ & 1.91 & $0.94-3.89$ \\
\hline
\end{tabular}

$p$-value for the maximum likelihood ratio test obtained using Poisson regression.

$\mathrm{BF}=$ breastfeeding; $\mathrm{IF}=$ infant feeding. 
for these foods.

The "snacks" pattern, characterized by bakery products (breads, cakes and biscuits), legumes, fats and coffee, shows an approximation of infant feeding to that of adult individuals, as was observed in the POF 2008-2009, which found greater consumption of bread, beans and coffee by adult Brazilians, $64.5 \%, 72.8 \%$ and $79 \%$ respectively, and $29 \%$ and $13.4 \%$ for cakes and cookies respectively. 18

Receiving guidance on infant feeding was associated with greater adherence to both the "mixed" pattern and the "porridge" pattern. Thus, it is inferred that mothers are receiving guidance from health professionals on adequate foods, which should be offered during the child's food introduction period, since the supply of fruits, vegetables and protein foods was practiced. In contrast, the supply of ultra-processed foods such as sweetened yoghurts, rich in artificial color additives and of low nutritional value persists. Possibly the great appeal of the media in relation to the advertising of baby foods is a determining factor in the adoption of this practice.

The professional guidance provided to mothers is an important source of knowledge and a factor that encourages breastfeeding, since mothers are usually insecure in the puerperium and due to lack of support, guidance and low level of knowledge, they end up abandoning exclusive breastfeeding or even early weaning. 19 Caldas et al. 20 found a significant relationship between longer duration of $\mathrm{BF}$ and receiving instructions on breastfeeding in the puerperium and when the place where these guidelines were received was the health unit. This fact shows that guidance is essential for the continuation of breastfeeding in the postpartum period.

The study carried out by Bortolini and Vitolo ${ }^{21}$ also demonstrated that health professionals' guidelines on BF and complementary feeding helped mothers to adopt healthier eating practices. Other studies have shown effectiveness in nutritional guidelines, with improvement in the quality of food offered and with a positive impact on EBF.22,23

On the other hand, the fact that these mothers who were guided have greater adherence to the "porridge" pattern may point out that not always guiding mothers and family members is a guarantee of compliance with the recommendations of $\mathrm{BF}$ and healthy complementary food. A study carried out in Porto Alegre, Rio Grande do Sul, showed that 47\% of mothers reported not following the guidelines received in health units. Of these, $45.7 \%$ did not recognize the importance of nutrition for the child's health, making it difficult to improve infant nutrition. 23
The basis of a healthy diet should be fresh or minimally processed foods, reduced or free of ultraprocessed foods, and should start in the first years of life. In addition, it is important to highlight that the act of eating is cultural and involves the preservation and transmission of knowledge of the dietary history of the families. The choices of foods to be introduced in complementary food should follow the habits of the family and prioritize local products. Implementing these recommendations, directly linked to the quality of infant feeding, is a major challenge, requiring the adoption of strategies that are effective in influencing the population. 3,24

In addition, the association between receiving guidance and adherence to the "porridge" pattern highlights the strong appeal of the culture of using porridge as an important food for children. Lima et al. 19 reveal in an article about social representations of adolescent mothers about food in the first year of life, that the consecration of the use of porridge in this age group is very strong. Even when mothers receive guidance on $\mathrm{BF}$ and the introduction of solids, they continue to offer this preparation to their children, most of the time, with added sugar, as was observed in the present study.

The early insertion of porridges or their use as a substitute for breast milk or meals composed of fruits, vegetables, meats and cereals, can lead the children to inadequate food consumption, due to the excess of sugars and flours for the preparation of porridges, which lead to deficient consumption of micronutrients and increased consumption of calories. The increase in caloric consumption, with the use of porridges, results in an increase in the weight of children and this can be misinterpreted by families as an adequate nutritional status. However, there is a risk of compromising biochemical parameters, especially those related to the lack of micronutrients. 25

Previous experience with breastfeeding showed greater adherence to the "porridge" pattern. The experience gained from the practice of breastfeeding does not always guarantee successful breastfeeding with the next child. Breastfeeding is permeated with determinants that may or may not guarantee its maintenance and the various difficulties that may affect the mother-child binomial during the breastfeeding period, such as discomfort and pain, physical and mental burnout and breast problems may be responsible for low persistence in the breastfeeding process 19,26 and this can lead to negative and frustrating experiences that interfere with the breastfeeding of subsequent children, leading to the early introduction of other foods. 
Another finding of the present study showed that children of mothers with overweight or obesity (BMI $\geq 25 \mathrm{~m} / \mathrm{kg}^{2}$ ) had less adherence to the "snacks" pattern. Unlike a study conducted in Japan with 758 children aged 16 to 24 months who found no association between maternal BMI and adherence to dietary patterns. ${ }^{27}$

In Rio Grande do Sul, a study on the dietary pattern of children aged 12, 24 and 48 months showed a strong association with social (maternal education, socioeconomic status and child care) and behavioral characteristics (duration of breastfeeding, bottle feeding and use of pacifiers). ${ }^{28}$ Lim et al., ${ }^{29}$ in Singapore showed an association between schooling and one of the patterns found, and Smithers et al.,30 in England, observed a correlation between patterns and maternal age, education and BMI, in addition to the number of children. In the present study, such maternal variables were not associated with the patterns identified.

As limitations of the study, we can mention the option of using only one R24h, which was due to the fact that the information on the consumption of just one day is acceptable when dealing with populations with very monotonous food.12 Many children were in the process introduction of complementary feeding, which means that the variation in feeding in a short period of time is small. Another limitation would be the use of a "free" sample, for convenience, which does not allow the generalization of the results; however, it points to an advance in terms of new studies on dietary patterns of children under two years.

The present study identified three eating patterns in children under two years of age: "mixed", "porridge" and "snacks.

Guidance on infant feeding showed greater adherence to the "mixed" and "porridge" patterns and guidance on breastfeeding, less adherence to the "snacks" pattern. The previous experience with breastfeeding showed greater adherence to the "porridge pattern and maternal overweight and obesity led to less adherence to the" snacks "pattern.

\section{References}

1. Cunha AJLA, Leite AJM, Almeida IS. The pediatrician's role in the first thousand days of the child: the pursuit of healthy nutrition and development. J Pediatr. 2015; 91 (6): 44-51

2. Mozetic RM, Silva SDC, Ganen AP. A importância da nutrição nos primeiros mil dias. Revista Eletrônica Acervo Saúde. 2016; 8 (2): 876-84.
In addition, it was possible to identify that ultraprocessed foods and porridges stood out as a widely used practice, even by mothers who received guidance on infant feeding.

The association between maternal variables and dietary patterns highlighted the importance of professional guidance in adhering to a more varied consumption pattern, which includes different food groups. Primary healthcare professionals can take advantage of the consultation time, both of the pregnant women and the nursing mothers, to enhance the experience of breastfeeding and reinforce the nonuse of ultra-processed foods and porridges in the first years of life.

The results of this study can serve as a subsidy to direct educational actions on infant feeding in primary care, as well as new studies on dietary patterns in children under two years of age, in the short and medium term.

\section{Acknowledgement}

To the National Council for Scientific and Technological Development (Edital Universal 14/2013 - CNPq; Process: 484077/2013-9) and to the Study and Research Group on Maternal and Child Nutrition (GPNUMI - Portuguese acronym).

\section{Authors' contribution}

Vasconcelos IN: contributed to data collection, literature review and manuscript writing. Brito IMVP: contributed with suggestions and critical review in the writing of the manuscript. Arruda SPM: performed the statistical analysis of the results and contributed with suggestions and critical review in the writing of the manuscript. Azevedo DV: oriented and coordinated the research project that gave rise to this work, being responsible for creating the original idea and guiding the writing of the manuscript; he coordinated the group that performed the data collection and tabulation. All authors approved the final version of the article.
3. Brasil. Ministério da Saúde. Secretaria de Atenção Primária à Saúde. Departamento de Promoção da Saúde. Guia alimentar para crianças brasileiras menores de 2 anos. 2. ed. Brasília, DF; 2019. 265 p.

4. Matos SMA, Barreto ML, Rodrigues LC, Oliveira VA Oliveira LPM, D'innocenzo S, Teles CAS, Pereira SRSP, Prado MS, Assis AMO. Padrões alimentares de crianças 
menores de cinco anos de idade residentes na capital em municípios da Bahia, Brasil, 1996 e 1999/2000. Cad Saúde Pública. 2014; 30 (1): 44-54.

5. Souza RLV, Madruga SW, Gigante DP, Santos IS, Barros AJD, Assunção MCS. Padrões alimentares e fatores associados entre crianças de um a seis anos de um município do sul do Brasil. Cad Saúde Pública. 2013; 29 (12): 2416-26.

6. Passanha A, Benício MHA, Venancio SI. Caracterização do consumo alimentar de lactentes paulistas com idade entre seis e doze meses. Ciênc Saúde Coletiva. 2020; 25 (1): 375 85.

7. Hearty AP, Gibney MJ. Comparison of cluster and principal component analysis techniques to derive dietary patterns in Irish adults. Br J Nutr. 2009; 101: 598-608.

8. Newby PK, Tucker KL. Empirically derived eating patterns using factor or cluster analysis: a review. Nutr Rev. 2004; 62 (5): 177-203.

9. United States Department Of Agriculture. A Series of Systematic Reviews on the Relationship Between Dietary Patterns and Health Outcomes. Virgínia; 2014.

10. Brasil. Ministério da Saúde. Secretaria de Atenção à Saúde. Departamento de Atenção Básica. Atenção ao pré-natal de baixo risco. 1. Ed. Brasília, DF; 2012. 318 p. (Série A Normas e Manuais Técnicos) (Cadernos de Atenção Básica n. 32).

11. Brasil. Ministério da Saúde. Secretaria de Atenção à Saúde. Departamento de Atenção Básica. Orientações para a coleta e análise de dados antropométricos em serviços de saúde: norma técnica do Sistema de Vigilância Alimentar e Nutricional - SISVAN. 1. ed. Brasília, DF; 2011. 76 p. (Série G. Estatística e Informação em Saúde).

12. Pereira RA, Sichieri R. Métodos de avaliação do consumo de alimentos. In: Kac G, Sichieri R, Gigante DP. Epidemiologia nutricional. Rio de Janeiro: Editora Fiocruz/Atheneu; 2007.

13. Drewett RF, Woolridgeb MW, Jacksonb DA, Imongc SM, Mangklabruks A, Wongsawasdii L, Chiowanich P, Amatayakul K, Baum JD. Relationships between nursing patterns, supplementary food intake and Breast-milk intake in a rural Thai population. Early Hum Dev. 1989; 20: 1323.

14. Nejar FF, Segall-Corrêa AM, Rea MF, Vianna RPT, Panigassi G. Padrões de aleitamento materno e adequação energética. Cad Saúde Pública. 2004; 20 (1): 64-71.

15. Garcia MT, Granado FS, Cardoso MA. Alimentação complementar e estado nutricional de crianças menores de dois anos atendidas no Programa Saúde da Família em Acrelândia, Acre, Amazônia Ocidental Brasileira. Cad Saúde Pública. 2011; 27 (2): 305-16

16. Olinto MTA. Padrões alimentares: análise de componentes principais. In: Epidemiologia Nutricional. Rio de Janeiro: Fiocruz; 2007

Received on June 8, 2020

Final version presented on 21 October 2020

Approved on February 25, 2021
17. Hu FB. Dietary pattern analysis: a new direction in nutritional epidemiology. Curr Opin Lipidol. 2002; 13 (1): 3-9.

18. Brasil. Ministério do Planejamento, Orçamento e Gestão. Instituto Brasileiro de Geografia e Estatística (IBGE). Diretoria de Pesquisas. Coordenação de Trabalho e Rendimento. Pesquisa de Orçamentos Familiares 20082009: análise do consumo alimentar pessoal no Brasil. Rio de Janeiro: Ministério do Planejamento, Orçamento e Gestão; 2011. 150 p

19. Lima APE, Javorsky M, Amorim RJM, Oliveira SC, Vasconcelos MGL. Práticas alimentares no primeiro ano de vida: representações sociais de mães adolescentes. Rev Bras Enferm. 2014; 67 (6): 965-71.

20. Caldas DRC, Oliveira SSS, Cunha EA, Oliveira MR, Landim LASR. Aleitamento Materno e Estado Nutricional de Crianças Menores de um Ano de um Município do Nordeste do Brasil. Ensaios Cienc Cienc Biol Agrar Saúde. 2016; 20 (1): 3-10.

21. Bortolini GA, Vitolo MR. The impact of systematic dietary counseling during the first year of life on prevalence rates of anemia and iron deficiency at 12-16 months. J Pediatr. 2012; 88 (1): 33-9.

22. Torigoe CY, Asakura L, Sachs A, Silva CVD, Abrão ACFV, Santos GMS, Coelho LC. Influência da orientação nutricional nas Práticas de alimentação complementar em lactentes. J Hum Growth Dev. 2012; 22 (1): 1-11.

23. Broilo MC, Louzada MLC, Drachler ML, Stenzel LM, Vitolo MR. Maternal perception and attitudes regarding healthcare professionals' guidelines on feeding practices in the child's first year of life. J Pediatr. 2013;89 (5): 485-91

24. Ortelan N, Neri DA, Benicio MHA. Práticas alimentares de lactentes brasileiros nascidos com baixo peso e fatores associados. Rev Saúde Pública. 2020; 54: 14

25. Farias Junior G, Osório MM. Padrão alimentar de crianças menores de cinco anos. Rev Nutr. 2005;18 (6): 793-802.

26. Parizotto J, Zorzi NT. Aleitamento Materno: fatores que levam ao desmame precoce no município de Passo Fundo, RS. O Mundo da Saúde São Paulo. 2008; 32 (4): 466-74.

27. Okubo H, Miyake Y, Sasaki S, Tanaka K, Murakami K, HirotaY. Dietary patterns in infancy and their associations with maternal socio-economic and lifestyle factors among 758 Japanese mother-child pairs: the Osaka Maternal and Child Health Study. Matern Child Nutr. 2012: 1-13.

28. Gatica G, Barros AJD, Madruga S, Matijasevich A, Santos IS. Food intake profiles of children aged 12, 24 and 48 months from the 2004 Pelotas (Brazil) birth cohort: an exploratory analysis using principal componentes. Int $\mathrm{J}$ Behav Nutr Phys Act. 2012; 9 (43): 1-10.

29. Lim GH, Toh JY, Aris IM, Chia A, Han WM, Saw SM, Godfrey KM, Gluckman PD, Chong YS, Yap F, Lee YS, Kramer MS, Chong MF. Dietary pattern trajectories from 6 to 12 months of age in a multi-ethnic Asian cohort. Nutrients. 2016; 8 (6): 365.

30. Smithers LG, Brazionis L, Golley RK, Mittinty MN, Northstone K, Emmett P, McNaughton SA, Campbell KJ, Lynch JW. Associations between dietary patterns at 6 and 15 months of age and sociodemographic factors. Eur J Clin Nutr. 2012; 66: 658-66. 